\title{
Free Space Optical Communications Utilizing MEMS Adaptive Optics Correction
}

C. A. Thompson, M. W. Kartz, L. M. Flath, S. C. Wilks, R. A. Young, G. W. Johnson, A. J. Ruggiero

This article was submitted to Conference \#4821 of the Society of Photo-Instrumentation Engineers (SPIE) 2002 Annual Meeting, Seattle, Washington, July 7-11, 2002

U.S. Department of Energy

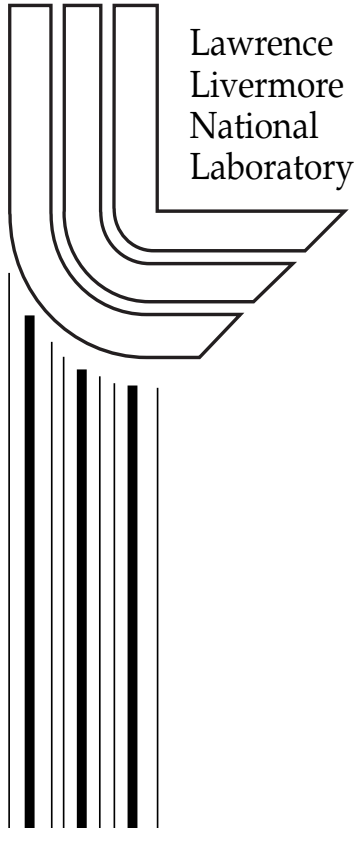

July 9, 2002 


\section{DISCLAIMER}

This document was prepared as an account of work sponsored by an agency of the United States Government. Neither the United States Government nor the University of California nor any of their employees, makes any warranty, express or implied, or assumes any legal liability or responsibility for the accuracy, completeness, or usefulness of any information, apparatus, product, or process disclosed, or represents that its use would not infringe privately owned rights. Reference herein to any specific commercial product, process, or service by trade name, trademark, manufacturer, or otherwise, does not necessarily constitute or imply its endorsement, recommendation, or favoring by the United States Government or the University of California. The views and opinions of authors expressed herein do not necessarily state or reflect those of the United States Government or the University of California, and shall not be used for advertising or product endorsement purposes.

This is a preprint of a paper intended for publication in a journal or proceedings. Since changes may be made before publication, this preprint is made available with the understanding that it will not be cited or reproduced without the permission of the author.

This report has been reproduced directly from the best available copy.

Available electronically at http://www.doc.gov/bridge

Available for a processing fee to U.S. Department of Energy

And its contractors in paper from

U.S. Department of Energy

Office of Scientific and Technical Information

P.O. Box 62

Oak Ridge, TN 37831-0062

Telephone: (865) 576-8401

Facsimile: (865) 576-5728

E-mail: reports@adonis.osti.gov

Available for the sale to the public from

U.S. Department of Commerce

National Technical Information Service

5285 Port Royal Road

Springfield, VA 22161

Telephone: (800) 553-6847

Facsimile: (703) 605-6900

E-mail: orders@ntis.fedworld.gov

Online ordering: http:/ / www.ntis.gov/ordering.htm

\section{OR}

Lawrence Livermore National Laboratory

Technical Information Department's Digital Library

http: / / www.llnl.gov/tid/Library.html 


\title{
Free Space Optical Communications Utilizing MEMS Adaptive Optics Correction
}

\author{
Charles A. Thompson*, Michael W. Kartz, Laurence M. Flath, Scott C. Wilks, \\ Richard A. Young, Gary W. Johnson, Anthony J. Ruggiero \\ Lawrence Livermore National Laboratory, Livermore, California, 94550
}

\begin{abstract}
Free space optical communications (FSO) are beginning to provide attractive alternatives to fiber-based solutions in many situations. Currently, a handful of companies provide fiberless alternatives specifically aimed at corporate intranet and sporting event video applications. These solutions are geared toward solving the "last mile" connectivity issues. There exists a potential need to extend this pathlength to distances much greater than a $1 \mathrm{~km}$, particularly for government and military applications. For cases of long distance optical propagation, atmospheric turbulence will ultimately limit the maximum achievable data rate. In this paper, we propose a method to improve signal quality through the use of adaptive optics. In particular, we show work in progress toward a high-speed, small footprint Adaptive Optics system for horizontal and slant path laser communications. Such a system relies heavily on recent progress in Micro-ElectroMechanical Systems (MEMS) deformable mirrors, as well as improved communication and computational components.
\end{abstract}

Keywords: Adaptive Optics, Free Space Optical, Free Space Laser Communications, MEMS, SATRN.

\section{INTRODUCTION}

Free Space Optical systems are becoming more popular as companies continue to solve the "last mile" problem. One of the benefits to FSO systems is short setup times. For instance, after the tragic terrorists incidents on September 11, FSO companies were hired to solve communications bottlenecks caused when the World Trade Center (WTC) towers collapsed $^{1,2}$. Many companies who relied on fiber-based solutions that ran through the WTC needed quick alternatives. FSO systems were quickly deployed because they allow for high bandwidth connections, require minimal infrastructure, and are essentially transparent to the end user (provided the weather cooperates).

An application space exists for free space optical communications over distances substantially longer than the "last mile". These include both military and civilian applications that require rapidly deployable portable communications infrastructures for the battlefield and in disaster relief, where transport of large data volumes is involved. For instance, a link set up in the WTC aftermath used free space optical communications across the Hudson River to a nearby New Jersey location. This link, operated at 1.6 miles, pushed the limits of the system ${ }^{1}$. As the desire to extend beyond the "last mile" becomes a reality, free space optical systems will be plagued by the effects of the atmosphere ${ }^{3-7}$ (Figure 1).

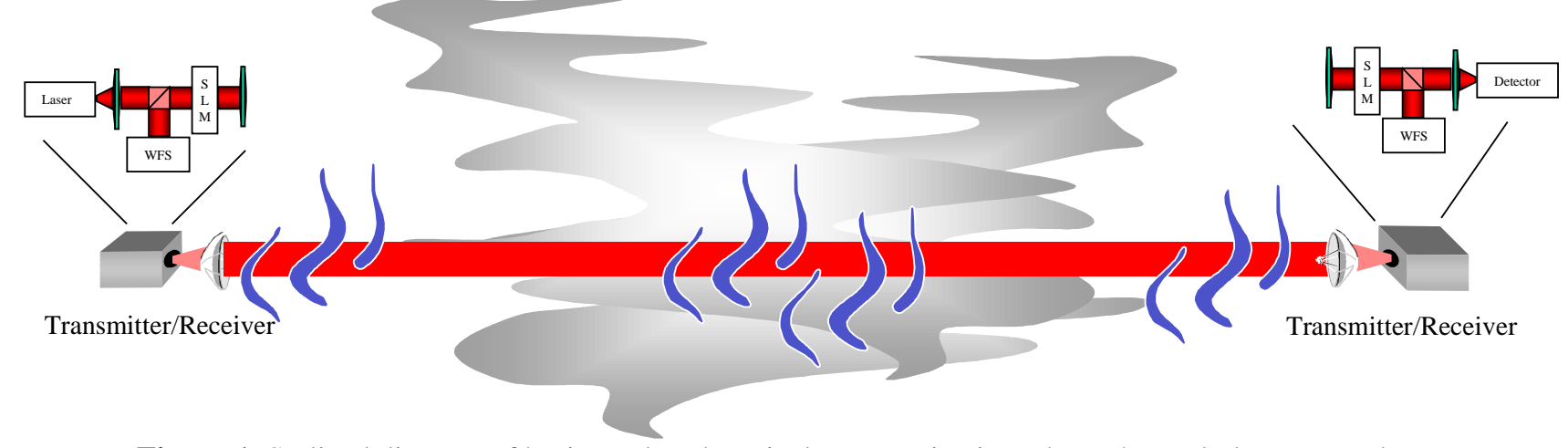

Figure 1. Stylized diagram of horizontal-path optical communications through a turbulent atmosphere.

* charlest@1lnl.gov; phone 1925 423-5907; L-183, 7000 East Avenue, Livermore, CA, 94550. 


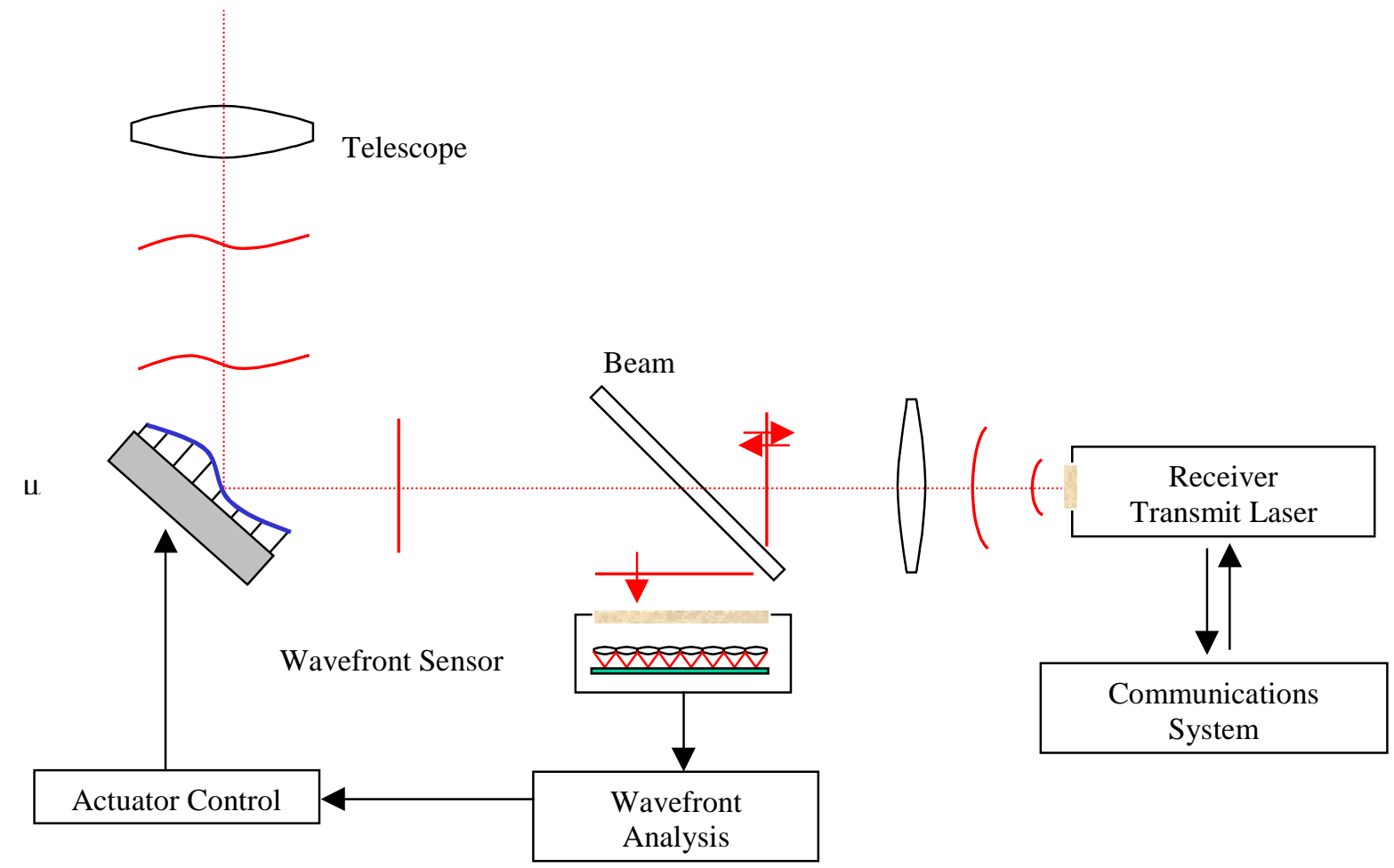

Figure 2. Schematic diagram detailing the operation of the envisioned Adaptive Optics system for use in a laser communications device. Note that the transmit laser and receiver detector share a common optical path (including the deformable mirror).

Under the SATRN project (Secure Air-optic Transport and Routing Network), we are addressing the long-range FSO problems. Establishing a link between ground, air, or sea-based mobile platforms in a wide variety of weather conditions leads to severe dynamic fading and pointing errors in addition to the usual propagation losses. In particular, turbulence will create a scintillated beam at the receiver. We are currently developing a suite of new techniques that includes MEMS and electro-optical Adaptive Optics, optical signal processing, high-power fiber amplifiers, and forward error correction. Our intent is to improve link availability on long-range (>10 km) links by focusing on optical solutions, thus maintaining protocol transparency. Nearly all of these technologies intrinsically depend upon the link hardware being coupled in single-mode (SM) fiber because it is scalable and transparent, and leverages commercial telecom components and standards. In this paper, we explore the use of MEMS adaptive optics to correct for the turbulence experienced in free space propagation. The use of adaptive optics systems based on MEMS will, in principle, allow us to extend free space communications distances, improve performance (from a Bit Error Rate, BER, standpoint), and overall transceiver size and power requirements.

Traditional adaptive optics systems are bulky, expensive and not easily fieldable. With new technology in MicroElectro-Mechanical Systems (MEMS) Spatial Light Modulators, as well as, smaller and faster computers, we are on the verge of creating high speed Adaptive Optics (AO) systems utilizing minimal space (Figure 2). This makes AO a practical solution for quick and easily fieldable applications (Figure 3). In this paper, we will show recent wavefront sensing performed on a long range FSO link, discuss Adaptive Optics design issues, and show our control system implementation architecture. 


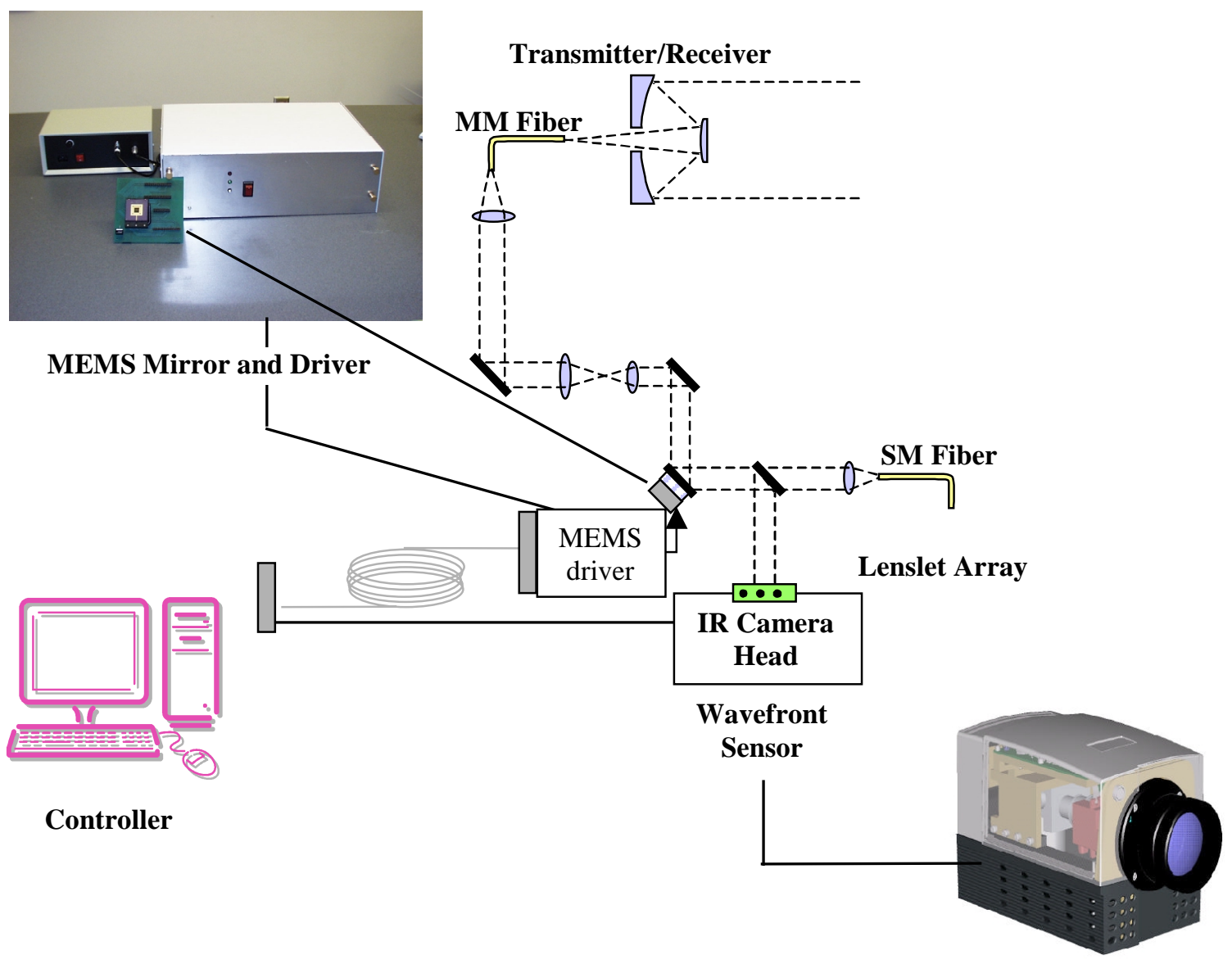

Figure 3. Schematic of the proposed Adaptive Optics system. The camera is the Indigo Phoenix DAS and the MEMS is the Boston Micromachines 140-actuator device.

\section{WAVEFRONT SENSOR EXPERIMENTATION}

We are presently performing wavefront sensor experiments on two FSO links in Livermore, California. The two links include a $1.3 \mathrm{~km}$ horizontal path located on-site at Lawrence Livermore National Laboratory (LLNL) and a $28.2 \mathrm{~km}$ slant path between LLNL and nearby Mount Diablo (Figure 4). On these links, we have demonstrated a WDM-based laser transceiver operating at $20 \mathrm{Gbit} / \mathrm{sec}$ on the $1.3 \mathrm{~km}$ horizontal path and $10 \mathrm{Gbit} / \mathrm{sec}$ on the $28.2 \mathrm{~km}$ link. Wavefront sensor measurements performed on the two links will provide validation of our simulation studies ${ }^{8}$ as well as verification on the Adaptive Optics system design.

Transceivers located at the LLNL site and on Mt. Diablo (Figure 5) were substantially the same except for the receive telescope. At the LLNL end, we used a $50.8 \mathrm{~cm}$ (20 inch) aperture Ritchey-Chretien (RC) telescope with a $4.1 \mathrm{~m}$ focal length (f/8.1), while at the Mt Diablo end it was a $40.6 \mathrm{~cm}$ (16 inch) aperture Cassegrain with a $5.8 \mathrm{~m}$ focal length (f/14.25). In both systems, light is collimated at the exit of the telescope by an appropriate lens. The visible and a small fraction of the infrared light is split off to a CCD camera for tracking purposes. Most of the infrared (signal) light is directed to a fast steering mirror with a $500 \mathrm{~Hz}$ bandwidth (Ball Aerospace model TT-25) that compensates for beam wander. Feedback is derived from a germanium position-sensitive detector and amplifier (On-Trak Photonics OT-301). At least $80 \%$ of the received $1550 \mathrm{~nm}$ energy is focused on either a 63 micron multimode or 8 micron single-mode receive fiber. 


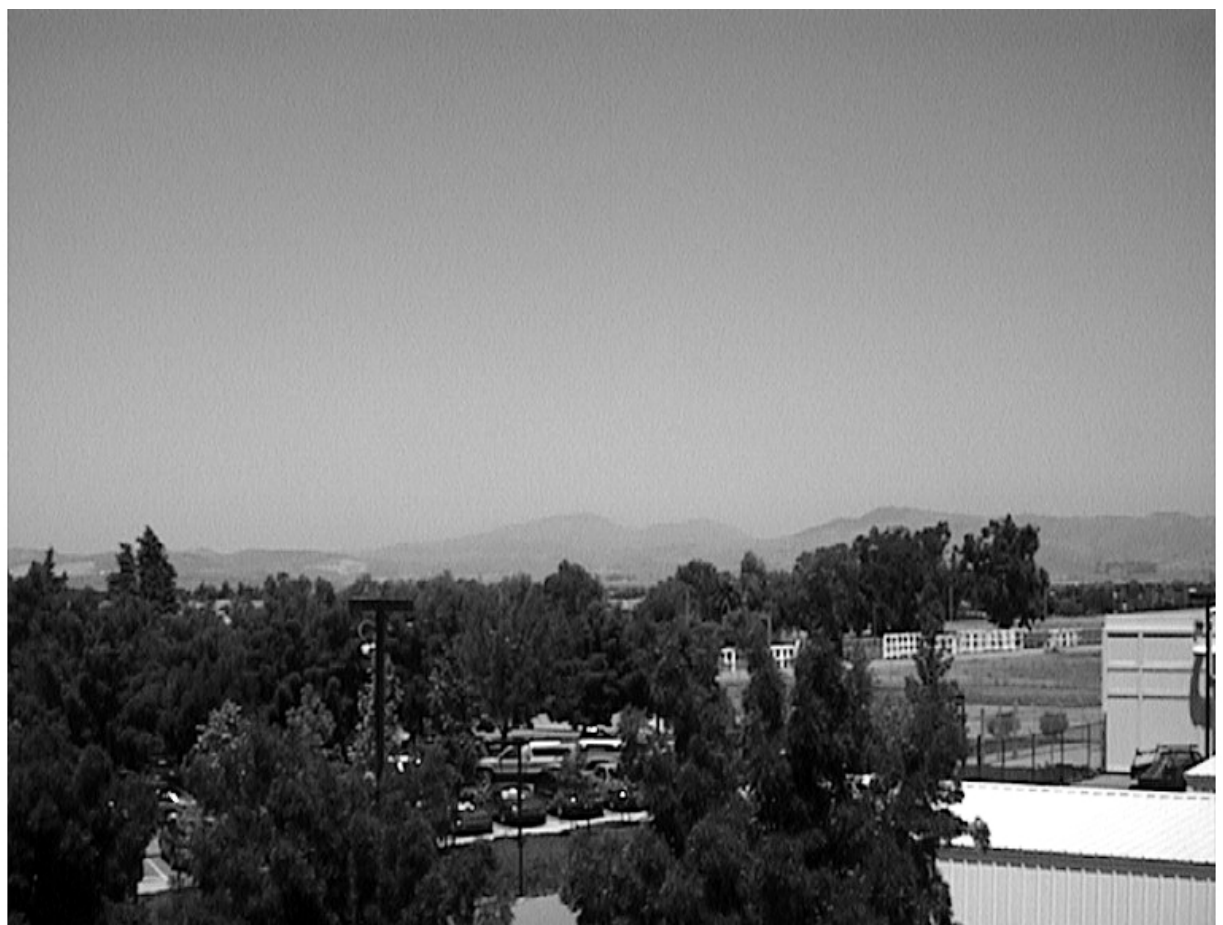

Figure 4. View of Mt. Diablo from LLNL.

At the LLNL site, a sample of the infrared light is sent to a Shack-Hartmann wavefront sensor. The sensor consists of an input telescope to reduce the beam size to match the lenslet array, a lenslet array, and an output telescope to reimage the spots onto the focal plane of an Indigo Phoenix DAS InGaS infrared digital camera.

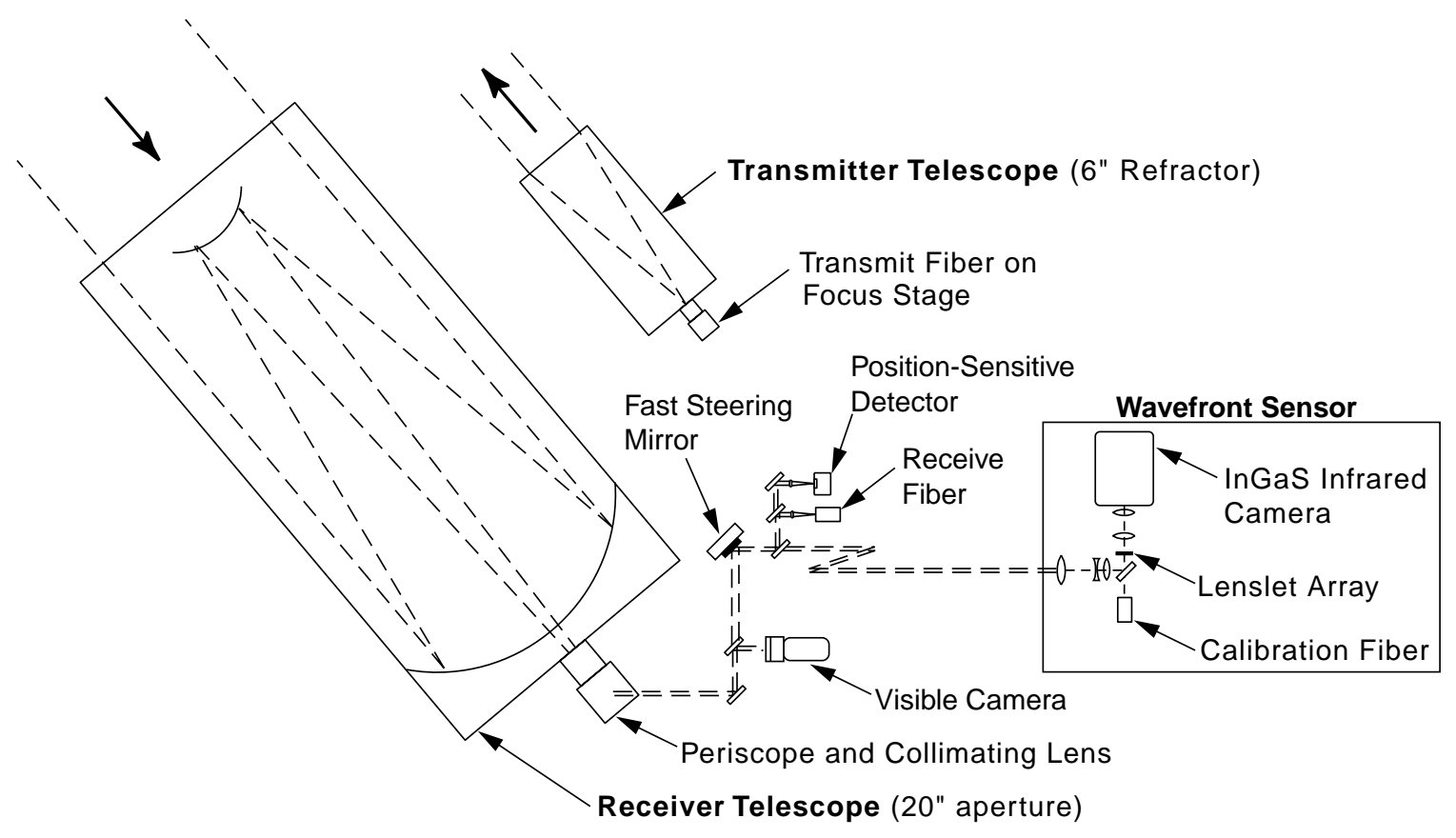

Figure 5. Simplified diagram of the tranceiver system located at LLNL site, with wavefront sensor. 
The sensor has been designed to allow for approximately a 20 x 20 array of Shack-Hartmann spots. As can be seen in Figures 6 and 7, the Shack-Hartmann array contains a central obscuration since it is conjugate to the primary of the RC telescope. The output of the Indigo camera has been windowed down to increase the frame rate to approximately 1.1 $\mathrm{kHz}$.

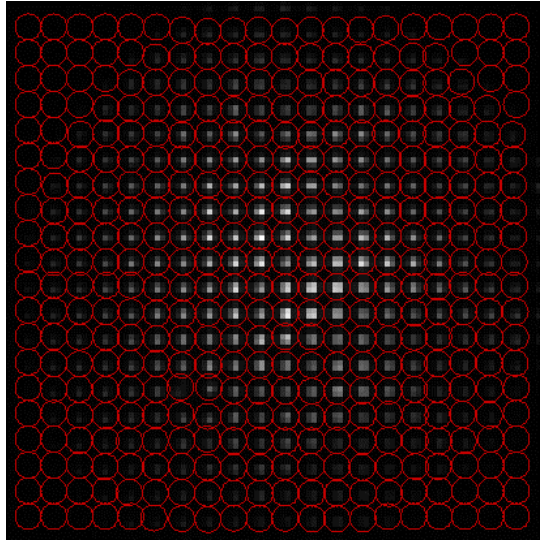

(a)

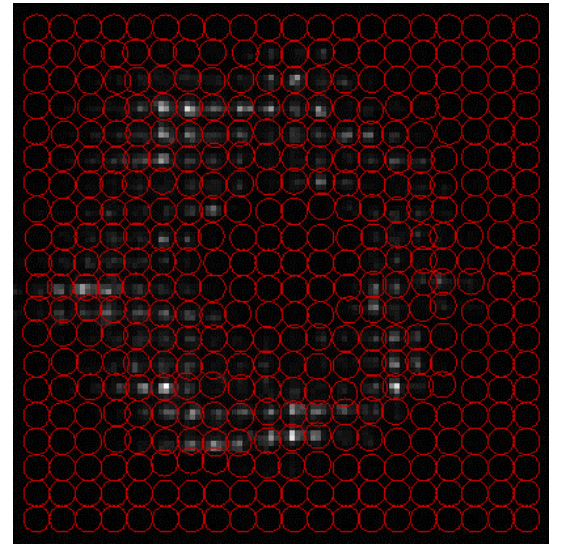

(b)

Figure 6. Wavefront sensor setup, with reference spot positions (a) and typical tracking of data in (b).

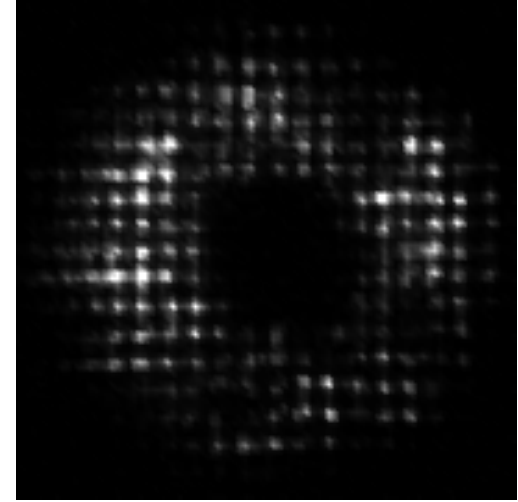

(a)

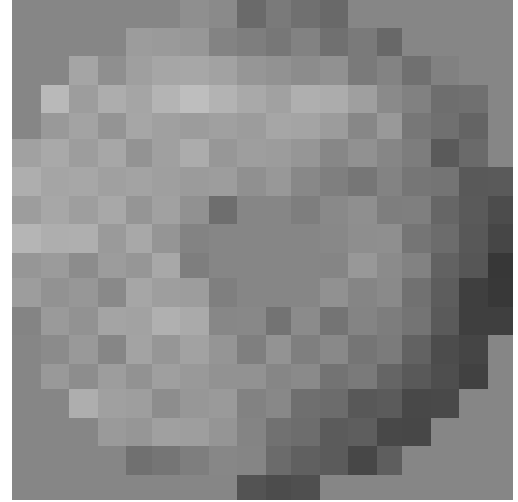

(b)

Figure 7. Wavefront sensor image (a) and resulting wavefront reconstruction (b).

The wavefront sensor system consisted of an Adaptive Optics Associates lenslet array with a spacing of $203 \mu \mathrm{m}$ and focal length of $5.8 \mathrm{~mm}$ (f/28.6) imaged via a 4:3 afocal telescope, and an Indigo Phoenix $1.55 \mu \mathrm{m}$-sensitive focal plane array with pixel pitch of $30 \mu \mathrm{m}$. The resulting spot pattern has a mean spacing of $\sim 5$ pixels.

Wavefront reconstruction was facilitated using the controller algorithm destined for the final adaptive optics system. Spot positions were computed with respect to the reference using a grayscale centroiding algorithm. While a high-speed system removed most of the tip/tilt, the result showed a residual focus error. The centroid offset of a particular spot (which represents the local slope of the wavefront) over the course of $1 / 2$ second (500 frames) is shown in Figure 8(a). One calculation performed by the spot tracking algorithm is the subaperture energy, which is the total of all of the pixel 
values in the area of interest (for this setup, 5 by 5 pixels centered on the reference position). Figure 8(b) clearly shows the effects of scintillation on the received intensity.

Calculated temporal statistics on the reconstruction are as follows (camera $t_{\text {frame }}=0.936 \mathrm{~ms}$ ). For subaperture energy, the given subaperture $(15,11)$ had a mean of 835 and $\sigma=707$ integrated ADUs. For a local reconstructed wavefront point, the mean was $-0.91 \mu \mathrm{m}$ with $\sigma=0.39 \mu \mathrm{m}(\sim \lambda / 4)$. The residual focus in the optical system gave a mean peak-tovalley wavefront over the entire unobscured aperture error of $2.87 \mu \mathrm{m}$, with a $\sigma=0.47 \mu \mathrm{m}$. These values should be regarded as preliminary, as effects such as crosstalk between subapertures have not been incorporated into the calculations (which will have the general effect of lowering the apparent wavefront slope).

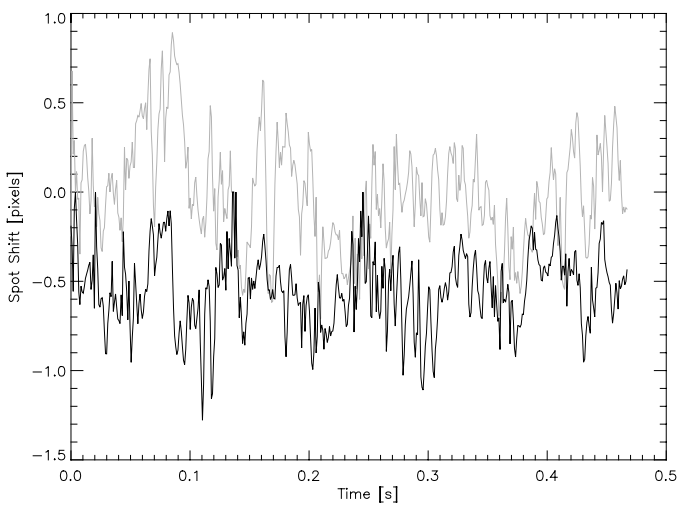

(a)

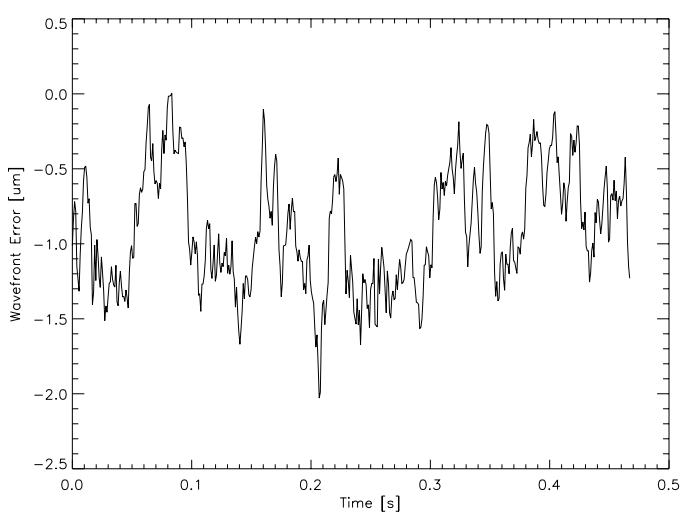

(c)

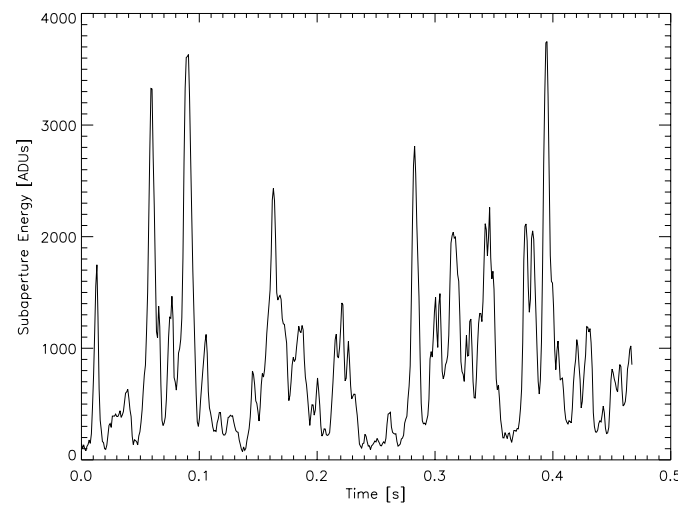

(b)

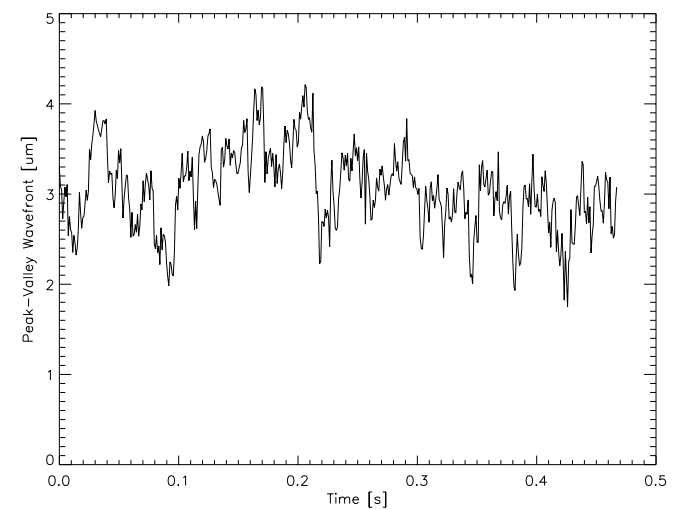

(d)

Figure 8. Wavefront reconstruction. For a particular subaperture $x=15, y=11$, measured from the topleft, the $\mathrm{x}$ - (black) and $\mathrm{y}$ - (gray) centroid offset with respect to reference (a), and integrated subaperture energy in (b). The variation (c) from reference for a local wavefront point $(x=16, y=12)$. In (d), the peak-to-valley wavefront for the entire aperture.

\section{SIMULATION STUDIES}

We are currently developing simulation capabilities for modeling atmospheric propagation and the effectiveness of various adaptive optics systems. The simulation capabilities are being currently bench-marked against our actual wavefront measurements. These simulations will allow for rapid determination of AO performance for a variety of applications and customer requirements. The simulation studies being performed for the SATRN project are presented 
in another paper within this volume ${ }^{8}$. In this paper, we will only briefly outline the simulation concept. Figure 9 shows a schematic diagram for how the simulations are performed. A set of random phase screens are created based on Kolmogorov statistics. For a snap-shot in time, the phase screens appear as 256 x 256 elements representing a $40 \mathrm{~cm} \mathrm{x}$ $40 \mathrm{~cm}$ spatial extent. Typical propagations rely on 10 equidistant phase screens. The propagation consists of Fourier propagating between each phase screen, apply the appropriate phase screen wavefront distortion and then propagate to the next, until finally propagating to the aperture of the telescope.

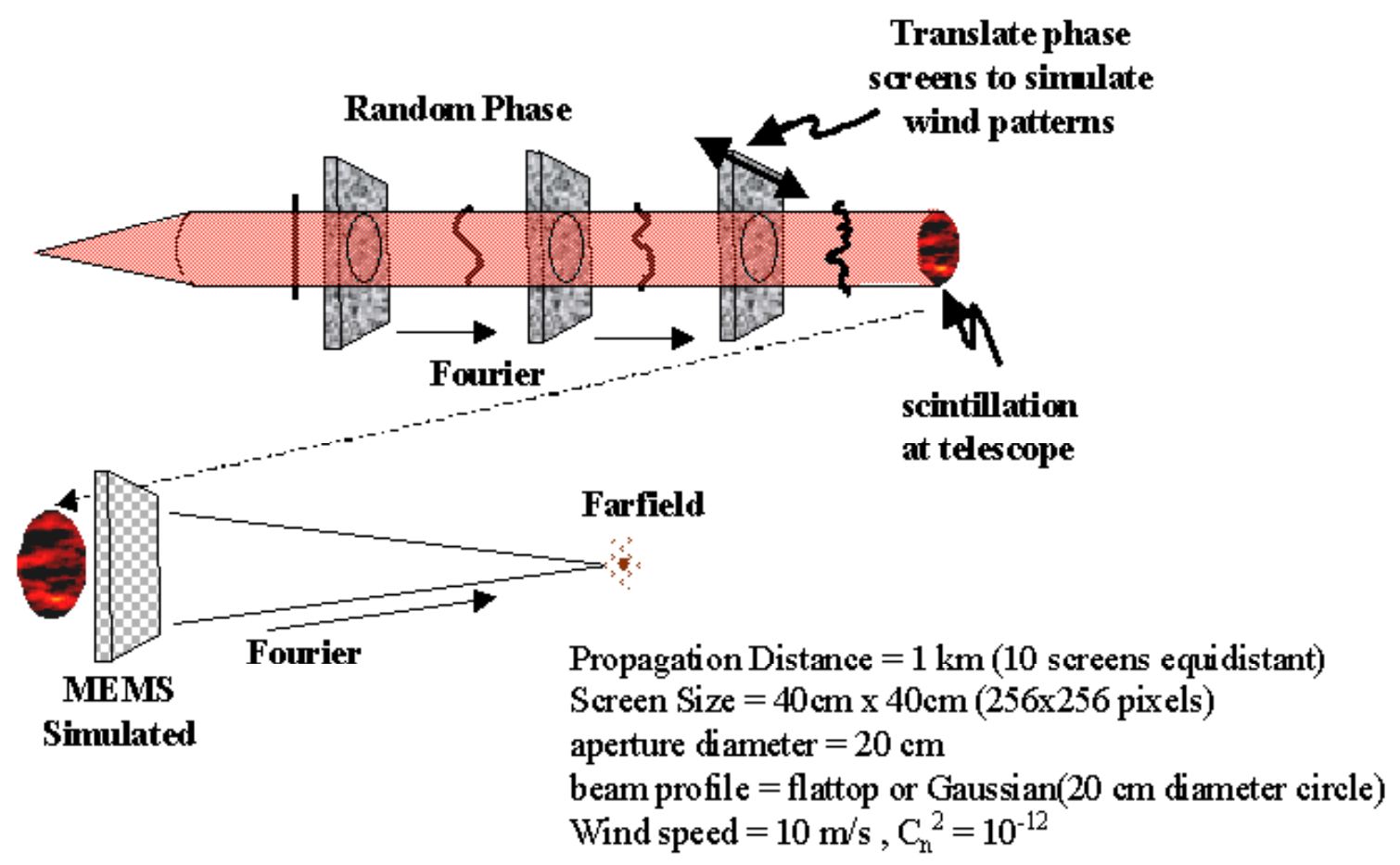

Figure 9. Diagram of free space optical simulation.

Current simulation studies include the capability of correcting the wavefront of the incoming light with a simulated Shack-Hartmann sensor and corresponding MEMS micro-mirror. Time series are created by translating the phase screens in a given direction so as to simulate a wind pattern (this requires creating the phase screens with an extent larger than 256 in at least one dimension).

We intend to validate the simulations with the actual measured data. In the end we hope to create a design tool which allows for simplified AO system design for various optical propagation distances and environments.

\section{CONTROL SYSTEM HARDWARE}

Commercially available components are used extensively in the hardware control system. The compute architecture is a standard PC with Intel Pentium central processing units (CPUs). Driver electronics for the MEMS devices, which support both high voltage MEMS and Deformable Mirror actuators at up to $300 \mathrm{~V}$, are the only custom components. The hardware architecture is designed to be modular in nature, utilizing multiple processors.

The controller is divided into four distinctive subsystems: Sensor, Controller, Modulator, and User Interface. Figure 10 shows a block diagram of this subsystem architecture. Inter-processor communication is accomplished via high- 
performance reflective memory. This hardware, through its $2 \mathrm{~Gb} / \mathrm{s}$ fiber optic interface, provides each subsystem with a full view of all object information and data.

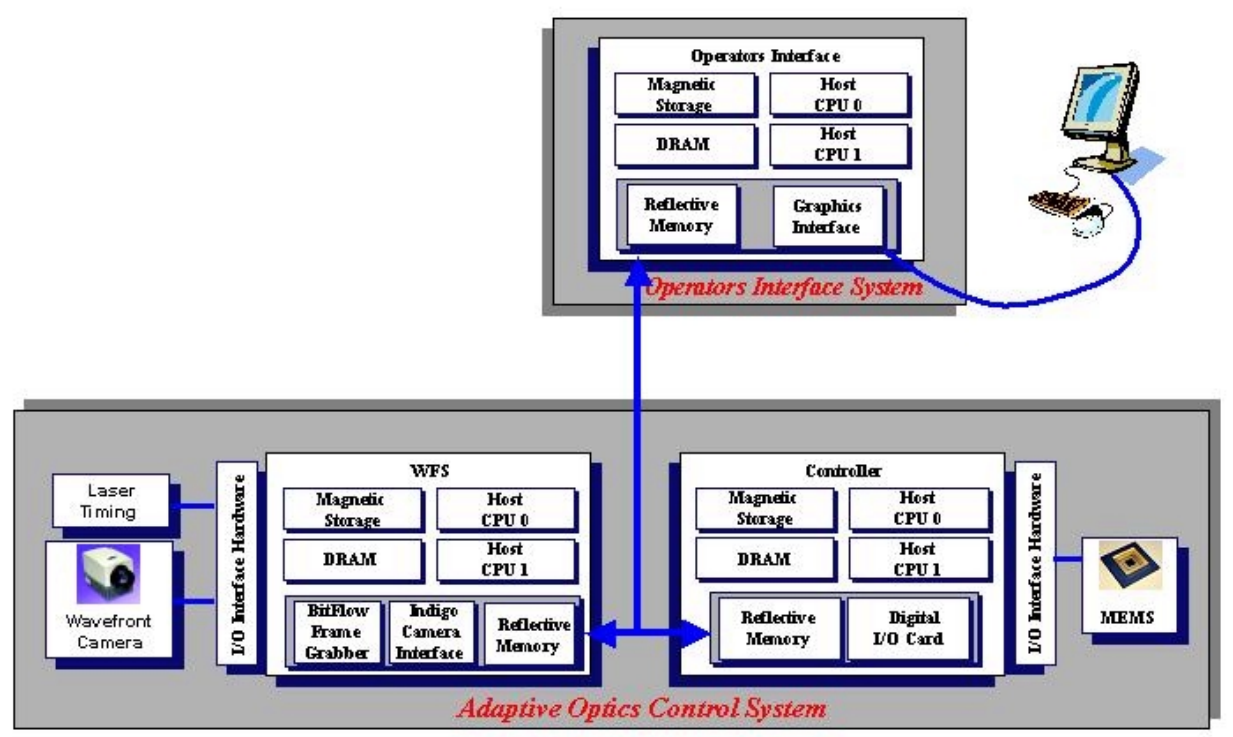

Figure 10. Hardware subsystem block diagram.

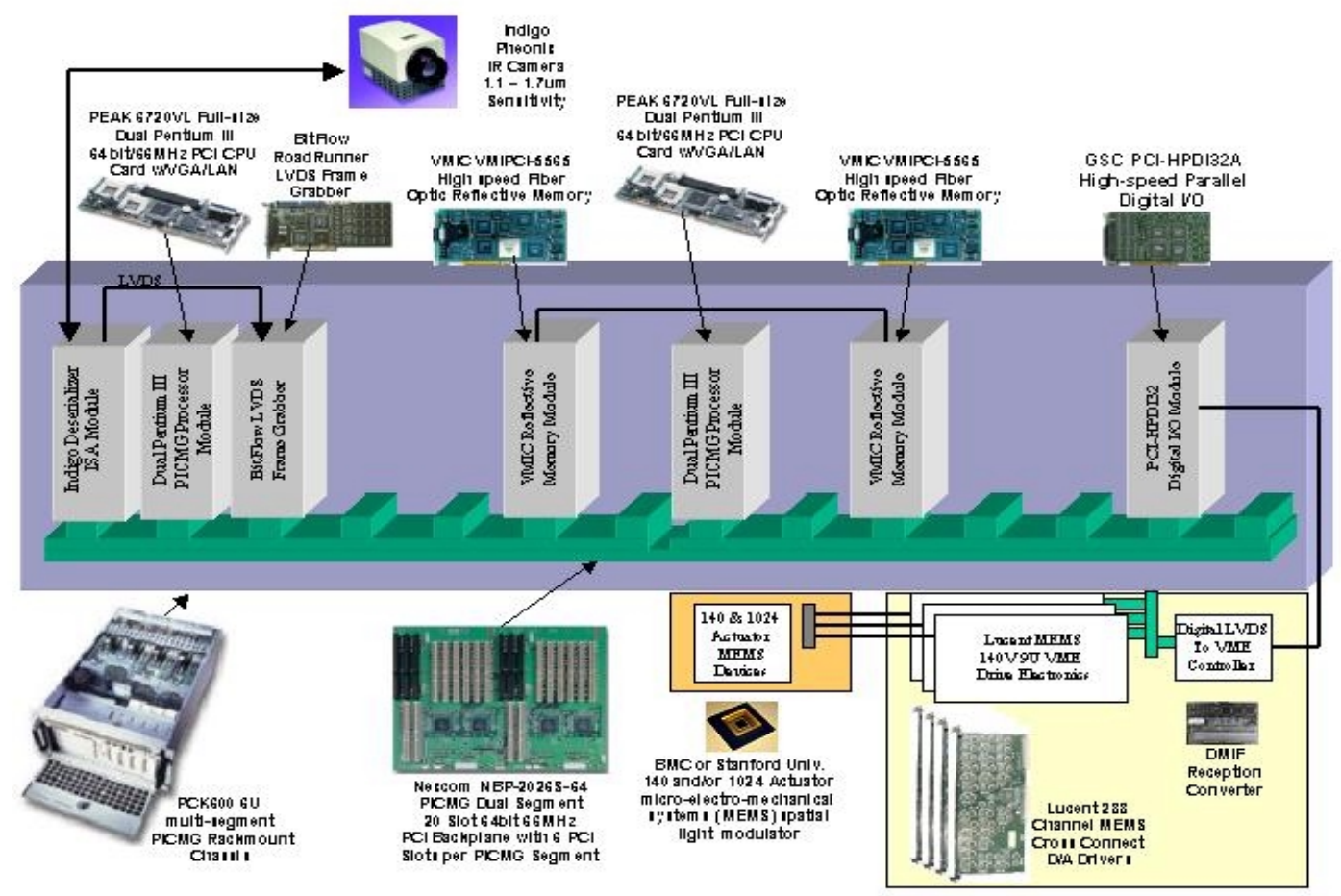

Figure 11. Hardware components. 
The software architecture mimics the hardware architecture by functioning as software subsystems. These subsystems directly overlay the hardware as described above. The software is written in C++ for the control system and with Java as the user interface. Data originates from the sensor and flows through the reflective memory, where the objects and member data is stored. Interrupts are used to implement the signaling mechanism between the software and hardware subsystems.

Full configuration for system operation is via XML files that identify operational parameters and system initialization. These files completely specify processor technology, sensor technology, control laws, modulation devices, and graphical configurations.

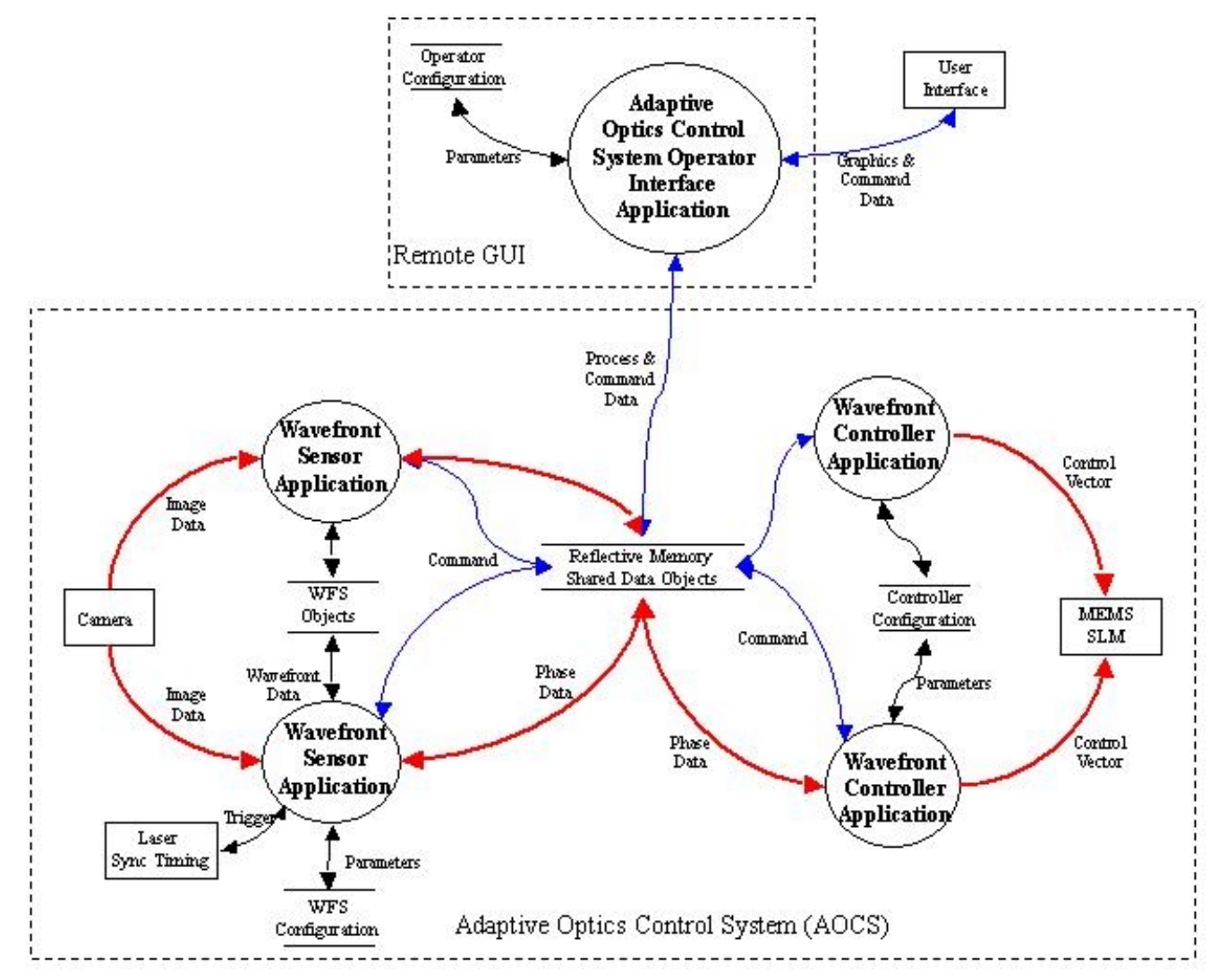

Figure 12. Adaptive optics control system data flow.

\section{CONCLUSIONS}

In this paper, we have introduced methods by which we are attempting to improve free space optical communications by use of Adaptive Optics. By use of AO, we hope to achieve longer pathlengths and/or reduced Bit Error Rates (BER). Our intended AO system is designed around a compact MEMS micro-deformable mirror, allowing for a compact optical system. In this paper, we have also discussed recent wavefront measurements performed on a $28.2 \mathrm{~km}$ slant path optical communication link. Wavefront measurements are being compared with simulated data such that we can develop sophisticated design tools useful in future field deployments. Finally, we briefly discussed hardware control systems, based on current available technology, that we believe will be useful in implementing a closed loop control system. By utilizing primarily off-the-shelf components, we believe there will be a substantial cost benefit savings and risk reduction. 


\section{ACKNOWLEDGEMENTS}

This work was performed under the auspices of the U.S. Department of Energy by University of California, Lawrence Livermore National Laboratory under Contract No. W-7405-Eng-48.

\section{REFERENCES}

1. Berman, D. K., "Lasers, Broadband Wireless Hookups Speed Data Around Lower Manhattan", The Wall Street Journal, Oct. 3, 2001.

2. Winters, Chris, "TeraBeam helps fix data lines in NYC", EJ Online, Oct. 10, 2001, www.eastsidejournal.com

3. Wisely, D.R.; McCullagh, M.J.; Eardley, P.L.; Smyth, P.P.; Luthra, D.; De Miranda, E.C.; Cole, R.S. " $4 \mathrm{~km}$ Terrestrial line-of-sight optical free space link operating at $155 \mathrm{Mbit} / \mathrm{s}$," Proceedings of the SPIE - The International Society for Optical Engineering, 2123, pp.108-119, 1994.

4. Levine, B.M.; Martinsen, E.A.; Wirth, A.; Jankevics, A.; Toledo-Quinones, M.; Landers, F.; Bruno, T.L. "Horizontal line-of-sight turbulence over near-ground paths and implications for adaptive optics corrections in laser communications," Proceedings of the SPIE - The International Society for Optical Engineering, 3125, pp. 354-365, 1997.

5. Barbier, P.R.; Rush, D.W.; Plett, M.L.; Polak-Dingels, P. "Performance improvement of a laser communication link incorporating adaptive optics," Proceedings of the SPIE - The International Society for Optical Engineering, 3432, pp.93-102, 1998.

6. Polejaev, V.I.; Ricklin, J.C. "Controlled phase diffuser for a laser communication," Proceedings of the SPIE - The International Society for Optical Engineering, 3432, pp.103-107, 1998.

7. Biswas, A.; Ceniceros, J.; Novak, M.; Jeganathan, M.; Portillo, A.; Erickson, D.; DePew, J.; Sanii, B.; Lesh, J.R., "45 km horizontal path optical link experiment," Proceedings of the SPIE - The International Society for Optical Engineering, 3615, pp.43-53,1999.

8. Wilks, S. C.; Brase, J. M.; Morris, J. R.; Olivier, S. S.; Henderson, J. R.; Thompson,, C. A., Kartz, M.; Ruggerio, A. J. "Modeling of Adaptive Optics-based free-space communications systems," Proceedings of the SPIE - The International Society for Optical Engineering, 4821, 2002. 